\title{
PREVALENCE OF PSYCHIATRIC COMORBIDITIES AND BEHAVIORAL RISK FACTORS IN CARDIOVASCULAR DISEASE PATIENTS
}

Sanjeev Shah, ${ }^{1}$ Chanda Sah, ${ }^{2}$ Manoj Dhungana, ${ }^{3}$ Mahmud Alam Khan ${ }^{4}$

\begin{abstract}
INTRODUCTION

Decades of research has revealed several links between cardiovascular diseases (CVDs) and mental illness, and has even suggested that both may actually cause one another. Emerging research is beginning to uncover high prevalence of behavioral risk factors in patients with mental illness that may lead to cardiovascular disease.
\end{abstract}

\section{MATERIAL AND METHODS}

A descriptive cross-sectional study was designed to assess the prevalence of psychiatric comorbidities in cardiovascular disease patients and to identify the behavioral risk factors in them. A semi-structured questionnaire including SelfReporting Questionnaire (SRQ-20) by WHO was used to screen psychiatric symptoms among 190 purposively selected samples. Data were analyzed by using descriptive and inferential statistics with SPSS version 20.0

\section{RESULTS}

Among the 190 respondents, 150 (78.95\%) were SRQ positive and table 1 shows majority (63.33\%) was male. Highest proportion $(60 \%)$ of the respondents was included in the age group of 40-64 years. Majority of cardiac morbidity was ischemic heart disease (55.79\%). Respondents diagnosed with some kind of cardiac disease were suffering from depression (53.33\%), anxiety disorder (38\%) and panic disorder (8.67\%). Behavioral risk factors present in respondents were smoking $(90 \%)$ and alcohol abuse $(90 \%)$ and more than half $(65.33 \%)$ and $(56 \%)$ had obesity and physical inactivity as behavioral risk factors respectively.

\section{CONCLUSION}

Health care professionals will need to expand their use of standardized screening tools that capture psychosocial factors in the CVDs population. Thus it can help in prevention and treatment of such comorbidities.

KEYWORDS Psychiatric comorbidities, Cardiovascular disease, Behavioral risk factors, Self-reporting questionnaire (SRQ-20)

1. Department of Psychiatry, Universal College of Medical Sciences, Bhairahawa, Rupandehi, Nepal

2. Universal College of Nursing Sciences, UCMS, Bhairahawa, Nepal

3. Department of Psychiatry, Devdaha Medical College and Research Institute, Rupandehi, Nepal

4. Department of Internal Medicine, Universal College of Medical Sciences, Bhairahawa, Nepal

DOI: http//doi.org/10.3126/jucms.v8i1.29838

\author{
For Correspondence \\ Dr. Sanjeev Shah \\ Department of Psychiatry \\ Universal College of Medical Sciences \\ Bhairahawa, Nepal \\ Email:shah_sanjeev@hotmail.com
}




\section{INTRODUCTION}

Cardiovascular disease (CVD) is the leading cause of death globally. In 2016, CVDs globally represent $31 \%$ of all global deaths. ${ }^{1}$ Nepal is also facing the surging burden of noncommunicable diseases (NCDs) where the prevalence of NCDs is $31 \%$. Among NCDs, CVD accounts $40 \%$ of all NCDs cases. ${ }^{2}$ Multi-sectorial action plan for the prevention and control of non-communicable diseases (2014-2020) estimated the $18 \%$ of the NCDs burden is due to mental illness. ${ }^{3}$ The comorbidity between psychiatric disorders and cardiovascular disease (CVD) has received growing attention in recent scientific literatures. Psychiatric disorders such as depression and anxiety represent an additional risk for Coronary Artery Disease (CAD) besides contributing to impair functioning for patients with CAD. ${ }^{4}$ A study conducted in Bikaner, India in 2001 , found high prevalence $(75 \%)$ of diagnosable psychiatric morbidity among patients attending cardiac OPD. Depression was the most common (38.67\%).

A Scottish health survey conducted in 2006 found that participants with episodes of psychiatric illness had higher risk of mortality where most of them were heavy smokers (odds ratio, 4.69; 95\% confidence interval, 3.79-5.82) and have low physical activity levels $(2.24 ; 1.75-2.87)$. In multivariate analyses, the association between history of a psychiatric episode and all-cause mortality was attenuated but remained statistically significant $(2.02 ; 95 \%$ confidence interval, 1.62-2.52; $\mathrm{P}<.001)$ after adjustments for psychosocial factors, smoking and physical activity. In this study it also showed the associations between psychiatric episodes and all-cause mortality (age and sex-adjusted hazard ratio, 3.55; 95\% confidence interval, 2.85-4.43) and cardiovascular mortality $(3.36 ; 2.17-5.21)$ were slightly strengthened. ${ }^{6,7}$

Poor health behaviors such as low physical activity, poorer dietary intake, smoking, alcohol abuse, are highly seen in patients with mental illness. This kind of poor health behaviors can lead to CVDs. Thus researchers designed this research study to assess the prevalence of psychiatric comorbidities in patients with cardiovascular diseases and to identify the behavioral risk factors in them.

\section{MATERIAL AND METHODS}

This cross sectional study was conducted from 5th May, 2019 to 16th November, 2019 among 190 purposively selected patients attending medicine/cardio OPD of Universal College of Medical Sciences-Teaching Hospital (UCMS-TH), Rupandehi. Ethical approval was taken from the institutional review committee of UCMS-TH. Administrative approval was obtained from UCMS-TH. Patients with severe mental illness, unconscious patients whose psychiatric evaluation was not possible and patients who needed immediate cardiac intervention were excluded from the study. After taking written informed consent, Self-Reporting Questionnaire (SRQ-20) was applied to screen psychiatric symptoms. Those who were SRQ positive were assessed by psychiatrist of the UCMS-TH.

Self-Reporting Questionnaire (SRQ-20) ${ }^{8,9}$ developed by WHO as an instrument designed to screen for psychiatric disturbances in developing countries. This instrument enables respondents from different cultures the opportunity 'to report the presence or absence of clearly defined symptoms. The SRQ-20 consists of 20 yes and no questions. If the number of 'yes' answers to the first 20 questions exceeds a predetermined number, it is likelythat the respondent is suffering from some form of mental disorder. A previous study showed the prevalenceof mental disorders in primary care clinics ranged from $10.6 \%$ to $17.7 \%$ (mean $13.9 \%$ ) in five of the seven centers studied.

The Nepali version of the SRQ used by Upadhyaya KD and Pol K (1998) and Adhikari and Denison (1999) was taken for screening purpose in this study. ${ }^{10,11}$ The questions of the SRQ, 12 are related to psychological and 8 to physical problems. A high cut-off point 10 was selected, according to earlier studies, for the SRQ in order to increase the specificity of the questionnaire.

Another tool used was semi structured socio-demographic questionnaire which included gender, age, marital status, type of family and education; behavioral risk factors, such as smoking, alcohol use, physical inactivity, obesity were obtained by asking related questionnaires. For instance, we asked the question "do you currently smoke?" Alcohol consumption habit was ascertained asking "have you consumed an alcoholic drink within the past 30 days". If yes, we estimate dan average amount of standard drinks per day. Weight was divided by square of height (in meters) to calculate Body Mass Index (BMI) of participants.

Descriptive statistics (frequency, percentage, mean and standard deviation) and inferential statistics (Chi-square tests and Karl Pearson's coefficient correlation for association) were used with SPSS version 20.0 for data analysis.

\section{RESULTS}

Among the 190 respondents, 150 (78.95\%) were SRQ positive and Table 1 shows majority $(63.33 \%)$ was male. Highest proportion $(60 \%)$ of the respondents was included in the age group of 40-64 years. Most (81.33\%) of them were living with spouse and majority (64\%) were literate. Maximum (53.33\%) respondents were from nuclear family. 
Table 1. Distribution of SRQ positive respondents according to socio-demographic variables

$(\mathrm{n}=150)$

\begin{tabular}{lll}
\hline $\begin{array}{l}\text { Socio-demographic } \\
\text { variables }\end{array}$ & Frequency & Percentage \\
\hline $\begin{array}{l}\text { Gender } \\
\text { Male }\end{array}$ & 95 & 63.33 \\
Female & 55 & 36.67 \\
$\begin{array}{l}\text { Age } \\
\text { 19-39 }\end{array}$ & 28 & 18.67 \\
$\begin{array}{l}\text { 40-64 } \\
\text { 65 \& above }\end{array}$ & 90 & 60 \\
Marital status & 32 & 21.33 \\
Living with spouse & 122 & 81.33 \\
$\begin{array}{l}\text { Single } \\
\text { Type of family }\end{array}$ & 28 & 18.67 \\
$\begin{array}{l}\text { Nuclear } \\
\text { Joint }\end{array}$ & 80 & 53.33 \\
Education & 70 & 46.67 \\
Literate & & 64 \\
Illiterate & 96 & 36 \\
\hline
\end{tabular}

As shown in table 2, majority of cardiac morbidity was ischemic heart disease $(55.79 \%)$.

Table 2. Distribution of cardiovascular diseases among the respondents $(n=190)$

\begin{tabular}{lll}
\hline Cardiovascular diseases & Frequency & Percentage \\
\hline Ischemic heart disease & 106 & 55.79 \\
Heart failure & 25 & 13.16 \\
Cardiomyopathy & 23 & 12.1 \\
Rheumatic heart disease & 20 & 10.53 \\
Valvular heart disease & 16 & 8.42 \\
\hline
\end{tabular}

Figure 1 shows majority of SRQ positive respondents diagnosed with some kind of cardiac disease were suffering from depression $(53.33 \%)$, anxiety disorder (38\%) and panic disorder $(8.67 \%)$.

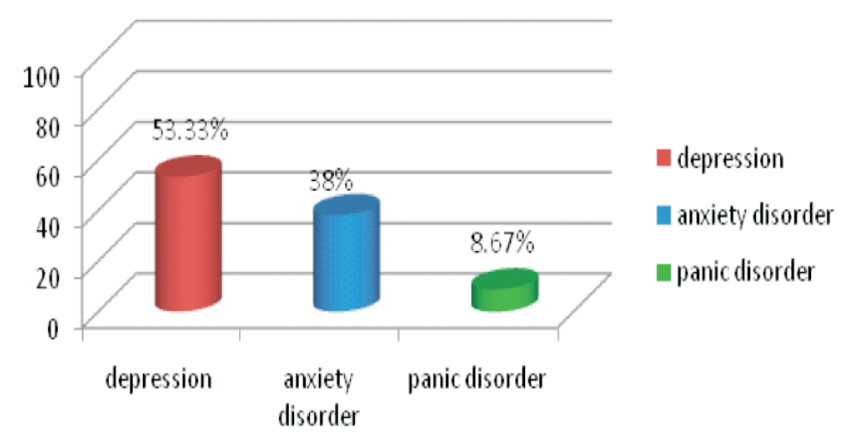

Figure 1. Different types of psychiatric disorders among the respondents $(n=150)$

Table 3 shows majority of SRQ positive respondents had smoking (90\%) and alcohol abuse $(90 \%)$ as behavioral risk factors. More than half $(65.33 \%)$ and $(56 \%)$ had obesity and physical inactivity as behavioral risk factors respectively.
Table 3. Behavioral risk factors among the SRQ positive respondents $(n=150)$

\begin{tabular}{lll}
\hline Behavioral risk factors & Frequency & Percentage \\
\hline Smoking & 135 & 90 \\
Alcohol abuse & 135 & 90 \\
Physical inactivity & 84 & 56 \\
Obesity & 98 & 65.33 \\
\hline
\end{tabular}

\section{DISCUSSION}

Based on the findings of this study out of 190 respondents, $78.95 \%$ of respondents were suffering from psychiatric illness which is consistent with the study ${ }^{5}$ of Bikaner, India which shows that $75 \%$ of respondents were suffering from psychiatric illness among cardiac disease patients. In this study majority of cardiac morbidity was ischemic heart disease $(55.79 \%)$ which is not consistent with the study ${ }^{7}$ of Bangladesh, Dhaka which shows that most common cardiac morbidity was ischemic heart disease $(29.8 \%)$. In present study SRQ positive respondents diagnosed with some kind of cardiac disease were suffering from depression (53.33\%) and anxiety disorder (38\%) which is not consistent with the study ${ }^{12}$ of Miriam hospital, Rhode Island, United States which shows that respondents with cardiac disease were suffering from depression (20\%) and anxiety disorder (45\%). In this study patients with cardiac disease were suffering from panic disorder was $8.67 \%$ which is consistent with the study ${ }^{13}$ of Rio de Janeiro, Brazil which shows that panic disorder was among $10 \%$ respondents with cardiac disease.

Findings of this study showed that smoking and alcohol abuse was found in $90 \%$ of SRQ positive respondents as behavioral risk factors which is not consistent with the study ${ }^{14}$ of Bangalore, India which shows that smoking in $46.9 \%$ respondents and alcohol abuse in $45.4 \%$ respondents as behavioral risk factors. Small sample size and being unable to study individual cardiovascular diseases and its relationship with the psychiatric comorbidities and behavioral risk factors are the limitations of this study. Several of the measures, including smoking, alcohol abuse, obesity and physical activity were assessed by self-report. Health care professionals will need to expand their use of standardized screening tools that capture psychosocial factors in the CVDs population. Research covered a long interview with the potential to lead to participant fatigue. Thus, other information on nutrition, metabolic health or other biological mechanisms could not be obtained. However, trained interviewers used validated tool and interview schedule in measurement of smoking, alcohol abuse, physical inactivity and obesity. 


\section{CONCLUSION}

In present study, psychiatric comorbidities were high in CVDs patients. Thus it suggests that these comorbidities may become more frequent and more serious which can pose challenge to treat patients with CVDs. Larger and more systemic studies are needed to explore these findings further. Further research needs to be done to explore possible relationships among CVDs, psychiatric illness and behavioral risk factors.

\section{ACKNOWLEDGEMENT}

The researchers would like to acknowledge UCMS-TH for providing an opportunity to carry out this research. The researchers express heartfelt thanks to all who participated in the study for immense support and cooperation.

\section{CONFLICT OF INTEREST}

None

\section{REFERENCES}

1. World Health Organization Fact Sheet. Cardiovascular diseases (CVDs), 2017.

2. Bhandari GP, Angdembe MR, Dhimal M, Neupane S, Bhusal C. "State of non-communicable diseases in Nepal". BMC Public Health. 2014;14(1):23

3. http://nhrc.gov.np/projects/nepal-mental-health-survey-20172018

4. Sardinha A, Claudio Gil Soares de Araújo CGSD, Adriana Cardoso de Oliveira e Silva ACDO, Nardi AE. Prevalence of psychiatric disorders and health-related anxiety in cardiac patients. Rev Psiq Clin. 2011;(2):61-65.

5. Goyal A, Bhojak MM, Verma KK, Singhal A, Jhirwal OP, Bhojak M. Psychiatric morbidity among patients attending cardiac OPD. Indian J Psychiatry. 2015; 43(4):335-9.

6. Hamer M, Stamatakis E, Steptoe A. Psychiatric hospital admissions, behavioral risk factors, and all-cause mortality. Arch Intern Med. 2008;168(22):2474-2479.

7. Sultana B, Khan MZ R, Tarannum S, Jahan N, Ahmed AU, Alam MF. Psychiatric morbidity among patients in cardiac outpatient department. Bang J Psychiatry. 2015; 29(1): 1-4.

8. Harding TW, DeArango NV, Balzar J, et al. Mental disorders in primary health care: a study of their frequency and diagnosis in four developing countries. Psychological Medicine. 1980;10: 231-241.

9. WHO. User's guide to the Self-Reporting Questionnaire (SRQ). Geneva: World Health Organization. 1994.
10. Pol K, Upadhyaya KD. A mental health prevalence survey in two developing towns of western region. J Nepal Med Ass. 2003;42:328-30.

11. Adhikari KP and Denison BDB. Mental health in Nepal: A community survey of a village in South Lalitpur, Central Nepal. United Mission to Nepal, Kathmandu. 1999.

12. Serber ER, Todaro JF, Tilkemeier PL, Niaura R. Prevalence and characteristics of multiple psychiatric disorders in cardiac rehabilitation patients. J Cardiopilm Rehabil Prev. 2009; 29(3): 161-170.

13. Sardinha A., Araujo C. G. S., Silva A. C. O. Nardi A. E.Prevalence of psychiatric disorders and health-related anxiety in cardiac patients. Rev Psiq Clin. 2011;38(2): 61-5.

14. John S. Prevalence and pattern of psychiatric morbidity and health related quality of life in patients with ischemic heart disease in a tertiary care hospital. Indiain J Psychiatry. 2013; 55(4): 353-359. 